\title{
Hydrogen coadministration slows the development of COPD-like lung disease in a cigarette smoke-induced rat model
}

This article was published in the following Dove Press journal:

International Journal of COPD

2 May 2017

Number of times this article has been viewed

\author{
Xiaoyu Liul,* \\ Cuiqing $\mathrm{Ma}^{2, *}$ \\ Xiaoyu Wang' \\ Wenjing Wang' \\ Zhu Li' \\ Xiansheng Wang' \\ Pengyu Wang' \\ Wuzhuang Sun' \\ Baojian Xue ${ }^{3}$ \\ 'Department of Respiratory \\ Medicine, The First Hospital of Hebei \\ Medical University, ${ }^{2}$ Department of \\ Immunology, Hebei Medical University, \\ Shijiazhuang, ${ }^{3}$ Life Science Research \\ Center, Hebei North University, \\ Zhangjiakou, People's Republic \\ of China \\ *These authors contributed equally \\ to this work
}

Correspondence: Wuzhuang Sun Department of Respiratory Medicine, The First Hospital of Hebei Medical University, 89 Donggang Road, Shijiazhuang 05003 I, People's

Republic of China

Tel +86 I8633889856

Email sunwuzhuang2016@163.com

Baojian Xue

Life Science Research Center, Hebei North University, I I Zuan-shinan

Road, Zhangjiakou 075000, People's

Republic of China

Email baojian-xue@uiowa.edu
Background: Chronic obstructive pulmonary disease (COPD) is a progressive pulmonary disease caused by harmful gases or particles. Recent studies have shown that $2 \%$ hydrogen or hydrogen water is effective in the treatment and prevention of a variety of diseases. This study investigated the beneficial effects and the possible mechanisms of different hydrogen concentrations on COPD.

Methods: A rat COPD model was established through smoke exposure methods, and inhalation of different concentrations of hydrogen was used as the intervention. The daily condition of rats and the weight changes were observed; lung function and right ventricular hypertrophy index were assessed. Also, white blood cells were assessed in bronchoalveolar lavage fluid. Pathologic changes in the lung tissue were analyzed using light microscopy and electron microscopy; cardiovascular structure and pulmonary arterial pressure changes in rats were observed using ultrasonography. Tumor necrosis factor alpha, interleukin (IL)-6, IL-17, IL-23, matrix metalloproteinase-12, tissue inhibitor of metalloproteinase-1, caspase-3, caspase- 8 protein, and mRNA levels in the lung tissue were determined using immunohistochemistry, Western blot, and real-time polymerase chain reaction.

Results: The results showed that hydrogen inhalation significantly reduced the number of inflammatory cells in the bronchoalveolar lavage fluid, and the mRNA and protein expression levels of tumor necrosis factor alpha, IL-6, IL-17, IL-23, matrix metalloproteinase-12, caspase-3, and caspase- 8 , but increased the tissue inhibitor of metalloproteinase-1 expression. Furthermore, hydrogen inhalation ameliorated lung pathology, lung function, and cardiovascular function and reduced the right ventricular hypertrophy index. Inhalation of $22 \%$ and $41.6 \%$ hydrogen showed better outcome than inhalation of $2 \%$ hydrogen.

Conclusion: These results suggest that hydrogen inhalation slows the development of COPDlike lung disease in a cigarette smoke-induced rat model. Higher concentrations of hydrogen may represent a more effective way for the rat model.

Keywords: chronic obstructive pulmonary disease, hydrogen, inflammation

\section{Introduction}

Chronic obstructive pulmonary disease (COPD) is an inflammatory pulmonary disease caused by harmful gases or particles. ${ }^{1}$ It is primarily characterized by airway remodeling and airflow obstruction that shows progressive development. ${ }^{2}$ COPD is the world's fourth major cause of death that exhibits high incidence and mortality. ${ }^{3}$ COPD can be caused by many factors, ${ }^{4}$ among which smoking is a major risk factor. Smokingderived substances and chemicals can cause airway and vasculature inflammatory 
responses, which ultimately result in endothelial cell damage, pulmonary vascular remodeling, and emphysema.

It has been shown that the main mechanisms underlying COPD include airway and lung inflammation, an imbalance in the protease/antiprotease system, and oxidative stress. Increased expression of the inflammatory cytokines, tumor necrosis factor alpha (TNF- $\alpha$ ) and interleukin-6 (IL-6), has been demonstrated in COPD lung tissue, ${ }^{5-7}$ whereas an imbalance of the matrix metalloproteinase-12/tissue inhibitor of metalloproteinase-1 (MMP-12/TIMP-1) ratio has been confirmed as a contributor to the pathogenesis of COPD in a number of studies. ${ }^{8,9}$ Multifunctional cytokine TNF- $\alpha$ can enhance airway inflammation and airway smooth muscle regeneration, change airway smooth muscle function, and be involved in airway reconstruction, suggesting that TNF- $\alpha$ plays an important role in the development and progression of COPD. ${ }^{5}$ In patients with acute exacerbation of chronic obstructive pulmonary disease (AECOPD), TNF- $\alpha$, derived from activated alveolar macrophages stimulated with some antigens such as bacteria or virus, in turn, elicits alveolar macrophages and bronchial epithelial cells to generate IL-8. ${ }^{7}$ Although IL-8 is an important inflammatory factor, TNF- $\alpha$, obviously, is significant in the development of COPD. Apoptosis has also recently been found to be involved in COPD development, as indicated by increased expression of apoptosis-related proteins, such as caspase- 3 and caspase- $8 .{ }^{10,11}$ Up to now, the mechanism of apoptosis with COPD has been unclear, but it may be associated with abnormal levels of apoptosis regulatory factors in blood. Mitochondria, the key factor in COPD apoptosis, regulate apoptosis and release apoptotic mediators, such as cytochrome $c$, which can combine apoptotic proteaseactivating factor 1 and caspase- 9 to activate caspase-9, and the latter in turn activates subsequent caspase- 3 and cell apoptosis. ${ }^{12}$ Thus, the level of caspase- 3 activation is positively correlated with caspase- 9 activation. Therefore, we evaluated caspase- 3 as a biomarker of COPD apoptosis.

In the past 30 years, research in COPD has dramatically increased the quality of life for patients with COPD. However, there remains no cure despite major advances in understanding of the pathogenesis of COPD. COPD is mainly treated with drugs, such as bronchodilators and corticosteroids. In addition, the use of antioxidants and vitamin $\mathrm{D}$ is currently being investigated clinically, but the results have not been satisfactory to date. ${ }^{13,14}$ Recent basic and clinical studies have revealed that hydrogen is an important physiologic regulatory molecule. An early study from Dole et al in 1975 has shown that hydrogen can suppress tumor formation on animal skin through its antioxidant effect, ${ }^{15}$ but this notion did not attract academic attention until 2007. Ohsawa et al reported that hydrogen could improve a cerebral ischemia-reperfusion model. ${ }^{16}$ Hydrogen can also relieve the inflammatory response in the brain tissue of Alzheimer's disease model rats, inhibit the activation of mast cells, improve the conditions of cerebral hemorrhage, inhibit the inflammatory response in general, heal intestinal injury, and so on. ${ }^{17-19}$ Moreover, a growing number of studies have demonstrated that hydrogen or hydrogen water has therapeutic effects on multisystem diseases, such as diabetes, and diseases of the cardiovascular system, skin, and intestines.

Recent studies have shown that $2 \%$ hydrogen can mitigate lung injury through an antiapoptotic effect and by inhibiting the expression of inflammatory cytokines. ${ }^{20-22}$ In 2011, Liu et al proposed that hydrogen treatment might become a new and effective method for COPD, ${ }^{23}$ but there have been a few studies that experimentally determined this therapy for COPD. It is still uncertain whether hydrogen has effects on COPD, or whether different concentrations of hydrogen could have different effects on COPD. In this study, therefore, a cigarette smoke-induced rat model was established, and the effects of hydrogen in a cigarette smoke-induced rat model were investigated.

\section{Materials and methods Instruments and reagents}

A smoking device (JY-01 model; Shijiazhuang Jinyang Science and Technology Development Co., Ltd.), a hydroxide atomizer (AMS-H-01; Shanghai Asclepius Meditec Co., Ltd., Shijiazhuang, People's Republic of China), an AniRes2005 lung function system (Peking Biolab Tech Co., Beijing, People's Republic of China), scanning electron microscope (SEM; S-3500N; Hitachi Ltd., Tokyo, Japan), transmission electron microscope (TEM; H-3500; Hitachi Ltd.), and Vevo ultra-high-resolution ultrasound imaging system for small animals (Vevo2100; VisualSonics, Toronto, Canada) were used in this study. Fluorescence quantitative polymerase chain reaction (PCR) was performed with an ABI7500 (Applied Biosystems). Diamond brand cigarettes (tar: $13 \mathrm{mg}$, nicotine: $1.2 \mathrm{mg}$, flue gas carbon monoxide: $14 \mathrm{mg}$; Hebei Tobacco Company, Zhangjiakou, People's Republic of China) were used for producing the COPD model. Nitrogen $\left(15 \% \mathrm{O}_{2}+85 \% \mathrm{~N}_{2}\right)$ was purchased from Shijiazhuang Central Plains Specialty Gases Ltd., and a $2 \% \mathrm{H}_{2}$ gas mixture $\left(21 \% \mathrm{O}_{2}+2 \% \mathrm{H}_{2}+77 \% \mathrm{~N}_{2}\right)$ was purchased from Guangzhou Puyuan Gas Company Ltd. Anti-TNF- $\alpha$ (rat, ab6671, 1:100 in immunohistochemistry [IHC], 1:200 in Western blot [WB]; Abcam), anti-IL-6 (rat, ab9324, 1:2,000 in IHC, 1:2,000 in 
WB; Abcam), anti-IL-17 (rat, ab79056, 1:1,000 in IHC, 1:1,500 in WB; Abcam), anti-IL-23 (rat, ab175072, 1:400 in IHC, 1:1,500 in WB; Abcam), anti-MMP-12 (rat, ab66157, 1:500 in IHC, 1:3,000 in WB; Abcam), anti-caspase-3 (rat, ab44976, 1:500 in IHC, 1:500 in WB; Abcam), anti-caspase-8 (rat, ab25901, 1:1,000 in IHC, 1:2,000 in WB; Abcam), antiTIMP-1 (mouse, 10753-1-AP, 1:20 in IHC, 1:800 in WB; Beijing Biosynthesis Biotechnology Co., Ltd, Beijing, People's Republic of China) primary antibodies, and anti-rabbit and anti-mouse secondary antibodies (Abbkine, Reddlands, CA, USA) were used to determine protein expression levels. A bicinchoninic acid protein assay kit was obtained from Shanghai BestBio Beibo Biological. Redzol (Beijing SBS Genetech Co., Ltd., Beijing, People's Republic of China), a reverse transcription kit (RR040A; Takara ClonTech Inc.), and real-time PCR (RT-PCR) kit (RR820A; Takara ClonTech Inc.) were used for monitoring mRNA expression levels.

\section{Animal grouping and model establishment}

Healthy male Sprague-Dawley rats (7 weeks old, body weight $180 \pm 20 \mathrm{~g}$ ) were selected for the experiments (Certificate ID 1503119; Hebei Medical University Animal Experimental Center, Shijiazhuang, People's Republic of China). The animals were accommodated for 1 week before the experiment. The care of laboratory animals and the animal experimental operation conformed to Beijing Administration Rule of Laboratory Animals. The study protocol was approved by the Institutional Animal Care and Use Committee, Hebei Medical University. The rats were given a standard diet and water ad libitum.

The rats with COPD-like lung disease were established by the smoking method. ${ }^{24}$ Animals were randomized into the following five groups (10 rats in each group): control group, COPD group, low-hydrogen group (Hl group), intermediate hydrogen group (Hm group), and high-hydrogen group (Hh group). Cigarette smoke and hydrogen were actually coadministered during a 4-month period. Except for the control group, the other groups of rats were given passive smoke exposure in a fumigation chamber twice per day, with 10 cigarettes in each group, and with each exposure session for 1 hour and $>4$ hours between two cigarette smoke exposures, which was performed for a total of 4 months. After exposure to cigarette smoke for two times every day in the 4-month period, the $\mathrm{Hl}$ group was also given $21 \% \mathrm{O}_{2}+2 \% \mathrm{H}_{2}$ by inhalation and the $\mathrm{Hm}$ group was given $21 \% \mathrm{O}_{2}+22 \% \mathrm{H}_{2}$ by inhalation using a hydrogen atomizer and $15 \% \mathrm{O}_{2}+85 \% \mathrm{~N}_{2}$ at a flow rate of $1: 2$, whereas the Hh group was given $21 \% \mathrm{O}_{2}+41.6 \% \mathrm{H}_{2}$ by inhalation with a hydrogen atomizer and $100 \% \mathrm{~N}_{2}$ at a flow rate of 5:3. Hydrogen inhalation with oxygen meter and real-time monitoring of the concentration of hydrogen meter occurred once a day for 2 hours in a total of 4 months of cigarette exposure. The rats in the control group received no intervention over the 4 months of the experimental period.

\section{Lung function}

Lung function was evaluated by endotracheal intubation under sterile conditions, according to each rat's body weight, after administering anesthesia by intraperitoneal injection of $2 \%$ sodium pentobarbital ( $3 \mathrm{~mL} / \mathrm{kg}$ ). Six continuous spontaneous breathing cycles were observed, forced vital capacity (FVC) and forced expiratory volume in 0.2 second (FEV0.2) were measured, and FEV0.2/FVC was calculated. ${ }^{25}$

\section{Bronchoalveolar lavage fluid (BALF) and tissue sample collection}

Bronchoalveolar lavage was performed using a three-in/ three-out pattern of intratracheal instillation. The rats were anesthetized by an intraperitoneal injection of $2 \%$ pentobarbital sodium $(3 \mathrm{~mL} / \mathrm{kg})$. Tracheal intubation in aseptic conditions was then performed, and then $2 \mathrm{~mL}$ normal saline in syringe slowly into the lung through trachea. BALF was placed into sterile centrifuge tubes for total and differential white blood cell counts. The red blood cells in lung blood vessels were washed with ice-cold saline at room temperature. The anterior lobe of the right lung was placed into paraformaldehyde for fixation, and the remaining three right lung lobes were frozen in liquid nitrogen. It was done according to the method described previously. ${ }^{24}$

\section{Hematoxylin and eosin (HE) staining}

HE staining was done according to the method described previously. ${ }^{25}$ The lungs were fixed with buffered $4 \%$ paraformaldehyde for 24 hours and embedded into paraffin. The $4 \mu \mathrm{m}$ sections were stained with HE for routine histologic examination. Lung tissue pathologic changes were observed under a light microscope, and the mean linear interval, mean alveolar number (MAN), and bronchial wall thickness/ diameter (BWT/D) ratio were determined.

\section{Electron microscope}

Rats were sacrificed and samples of about $1 \times 1 \times 1 \mathrm{~mm}$ of the left lung tissue and $1 \times 1 \times 3 \mathrm{~mm}$ of the right ventricular $(\mathrm{RV})$ wall tissue were obtained. The samples were immediately placed in 4\% glutaraldehyde for front fixation and washed with phosphate buffer and osmium tetroxide for postfixation. 
The samples were exposed to gradient dehydration with acetone after a second wash step and embedded in epoxy resins. After polymerization, ultrathin sections were prepared, stained with uranyl acetate lead citrate staining, and observed under TEM. ${ }^{26}$ A sample of about $5 \times 5 \times 5 \mathrm{~mm}$ of the left lung tissue was fixed with $2.5 \%$ glutaraldehyde. After dehydration, the samples were embedded in epoxy resins, cut into ultrathin sections, and observed using SEM. ${ }^{27}$

\section{Ultrasound}

After the rats in each group were anesthetized and chest skin preparation was done, the mean pulmonary arterial pressure (mPAP) values, left ventricular ejection fraction (LVEF), end-diastolic RV anterior wall thickness (RVAWd), enddiastolic left ventricular anterior wall thickness, and enddiastolic left ventricular posterior wall thickness (LVPWd) in each group were measured using Vevo ultra high-resolution small animal ultrasound imaging system.

\section{Right ventricular hypertrophy index}

This was done by detaching and weighing the RV free wall followed by calculating the RV hypertrophy index $(\mathrm{RVHI})=(\mathrm{RV} /[\mathrm{LV}+\mathrm{S}]),{ }^{24}$ where LV is left ventricular and $\mathrm{S}$ refers to the ventricular septum. This factor was used as an indicator of the state of RV infarction and as an indirect indicator of pulmonary artery pressure.

\section{Immunohistochemistry}

The protein expression levels of TNF- $\alpha$, IL-6, IL-17, IL-23, MMP-12, TIMP-1, caspase-3, and caspase- 8 were assessed by IHC. ${ }^{24}$ The lungs were fixed with buffered $4 \%$ paraformaldehyde for 24 hours and embedded into paraffin. Phosphatebuffered saline was used to replace the primary antibody as a negative control. Primary antibodies and secondary antibody were added, with diaminobenzidine as the chromogenic, and then hematoxylin dyeing was performed. Staining was observed under an optical microscope.

\section{Western blotting}

The protein expression levels of TNF- $\alpha$, IL-6, IL-17, IL-23, MMP-12, TIMP-1, caspase-3, and caspase-8 in the tissues were measured using WB. ${ }^{28}$ Protein concentrations were determined by the method of bicinchoninic acid. In brief, equal amounts of protein samples $(10 \mu \mathrm{g})$ from different samples were loaded on sodium dodecyl sulfate-polyacrylamide gels. Proteins were then electrophoresed and transferred to a nitrocellulose membrane. After blocking nonspecific binding with nonfat dry milk, the membranes were incubated overnight with the primary antibodies. The membrane was probed with the corresponding secondary antibody for 1 hour at room temperature. A two-color infrared laser imaging analysis system was used for development and recording of results. Each experiment was repeated five times, and similar results were obtained.

\section{Real-time PCR}

RT-PCR was performed according to the method described previously. ${ }^{24}$ Primers for determining mRNA expression of genes encoding TNF- $\alpha$, IL-6, IL-17, IL-23, MMP-12, TIMP-1, caspase- 3 , and caspase- 8 are listed in Table 1 . Total RNA was extracted from rat lung tissues. After RNA quantification, $1 \mu \mathrm{g}$ total RNA was used for reverse transcription. The PCR mixture included SYBR Green $(10 \mu \mathrm{L})$, distilled $\mathrm{H}_{2} \mathrm{O}$ $(7 \mu \mathrm{L})$, PCR forward primer $(10 \mu \mathrm{M} ; 0.8 \mu \mathrm{L})$, PCR reverse primer $(10 \mu \mathrm{M} ; 0.8 \mu \mathrm{L})$, cDNA $1 \mu \mathrm{L}$, and $50 \times$ ROX II $(0.4$ $\mu \mathrm{L})$. The cycling conditions were as follows: $95^{\circ} \mathrm{C}$ for $30 \mathrm{~s}$ as an initial denaturation step, followed by 40 cycles, each consisting of $95^{\circ} \mathrm{C}$ for $5 \mathrm{~s}$ and $60^{\circ} \mathrm{C}$ for $34 \mathrm{~s}$. $\beta$-actin was used as the internal control. Data were expressed as fold change versus control using $2(-\Delta \Delta \mathrm{Ct})$ method.

\section{Statistical analysis}

All data were analyzed by SPSS 21.0 statistical software and presented as mean \pm standard deviation (SD). Comparison of the mean among groups was made by one-way analysis of variance. Pairwise comparisons with homogeneity of variance were performed using the Student-Newman-Keuls method. $P<0.05$ was considered to indicate statistically significant differences.

Table I Primers of reverse transcription PCR analysis for genes

\begin{tabular}{lll}
\hline Primer & Primer sequence (5'-3') & $\begin{array}{l}\text { Product } \\
\text { length (bp) }\end{array}$ \\
\hline GADPH-F & TGAACGGGAAGCTCACTG & 119 \\
GADPH-R & GCTTCACCACCTTCTTGATG & \\
TNF- $\alpha-\mathrm{F}$ & CCTCTTCTCATTCCTGCTC & 124 \\
TNF- $\alpha-\mathrm{R}$ & CTTCTCCTCCTTGTTGGG & \\
IL-6-F & ATCTGCTCTGGTCTTCTGG & 78 \\
IL-6-R & TCTGGCTTTGTCTTTCTTGT & \\
IL-I7-F & TCATCCCTCAAAGCTCAGCG & 167 \\
IL-I7-R & TTCATTGCGGTGGAGAGTCC & \\
IL-23-F & AAAGGAGGTTGATAGAGGGT & $24 I$ \\
IL-23-R & TCTTAGTAGATCCATTTGTCCC & \\
MMP-I2-F & GTGCCCCAGAGGTCAAGATG & 245 \\
MMP-I2-R & GCATGGGCTAGTGTACCACC & \\
TIMP-I-F & CCTCTGGCATCCTCTTGTTG & 161 \\
TIMP-I-R & ATAACGCTGGTATAAGGTGGTC & \\
Caspase-3-F & TGGCATTGAGACAGACAG & 150 \\
Caspase-3-R & CAAAGGGACTGGATGAAC & \\
Caspase-8-F & CTGACTGGAGTGAACTATG & 267 \\
Caspase-8-R & GTGTGAAGATGGGCTGTG & \\
\hline
\end{tabular}




\section{Results}

\section{Hydrogen coadministration slows} weight loss in a cigarette smoke-induced rat model

There was no difference in baseline body weight among the five groups. After smoking, compared with the control group, the body weight of the COPD group was reduced $(P<0.05)$. Compared with the COPD group, the body weights of rats in the $\mathrm{Hl}$ and $\mathrm{Hh}$ groups were increased $(P<0.05)$, but that of the Hm group showed no change (Figure 1A). These results suggest that hydrogen coadministration slows weight loss in a cigarette smoke-induced rat model.

\section{Hydrogen coadministration ameliorates lung functions in a cigarette smoke- induced rat model}

FEV0.2 and FEV0.2/FVC in the COPD group were significantly lower; however, FVC was higher than that in the control group (all $P<0.01$ ). Compared with the COPD group, these were significantly increased; however, FVC was reduced in the $\mathrm{Hl}, \mathrm{Hm}$, and $\mathrm{Hh}$ groups (all $P<0.01$ ). $\mathrm{FVC}$ in the $\mathrm{Hl}$ group was significantly lower than that in the Hh group $(P<0.01$, Figure $1 \mathrm{~B})$. These results suggest that hydrogen coadministration ameliorates the lung functions in a cigarette smoke-induced rat model.

\section{Hydrogen coadministration reduces the infiltration of inflammatory cells in a cigarette smoke-induced rat model}

As expected, the number of total white blood cells, neutrophil granulocytes, and macrophages were significantly increased in the BALF of the COPD group (all $P<0.01$ ). Compared with the COPD group, these cells were decreased in the Hl, Hm, and Hh groups $(P<0.01$ or $P<0.05)$. There was no significant difference between the $\mathrm{Hm}$ and $\mathrm{Hh}$ groups in these cell numbers, but the $\mathrm{Hl}$ group showed a significant increase (all $P<0.01$; Figure 2). These results suggest that hydrogen coadministration reduces the infiltration of inflammatory cells in a cigarette smoke-induced rat model.
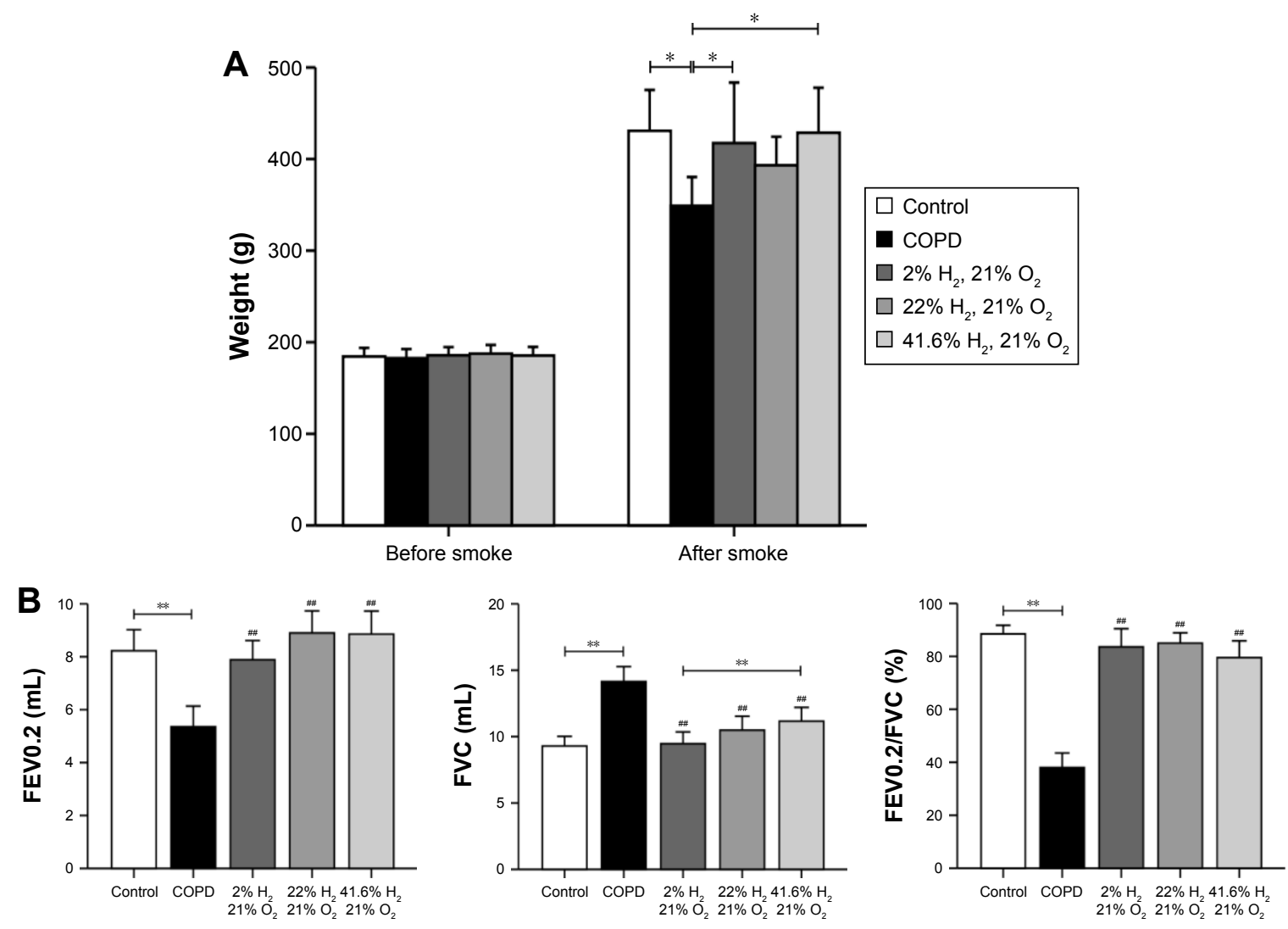

Figure I Effect of hydrogen on body weight and lung function in a cigarette smoke-induced rat model.

Notes: (A) Rats' body weights before and after smoking. (B) Lung function in rats. ( $\mathrm{n}=10$ for each group; ${ }^{\prime} P<0.0$ I compared with $C O P D$ group; $* P<0.05$, $* * P<0.0$ I).

Abbreviations: COPD, chronic obstructive pulmonary disease; FEV0.2, forced expiratory volume in 0.2 second; FEV $0.2 / F V C$, forced expiratory volume in 0.2 second/forced vital capacity; FVC, forced vital capacity. 

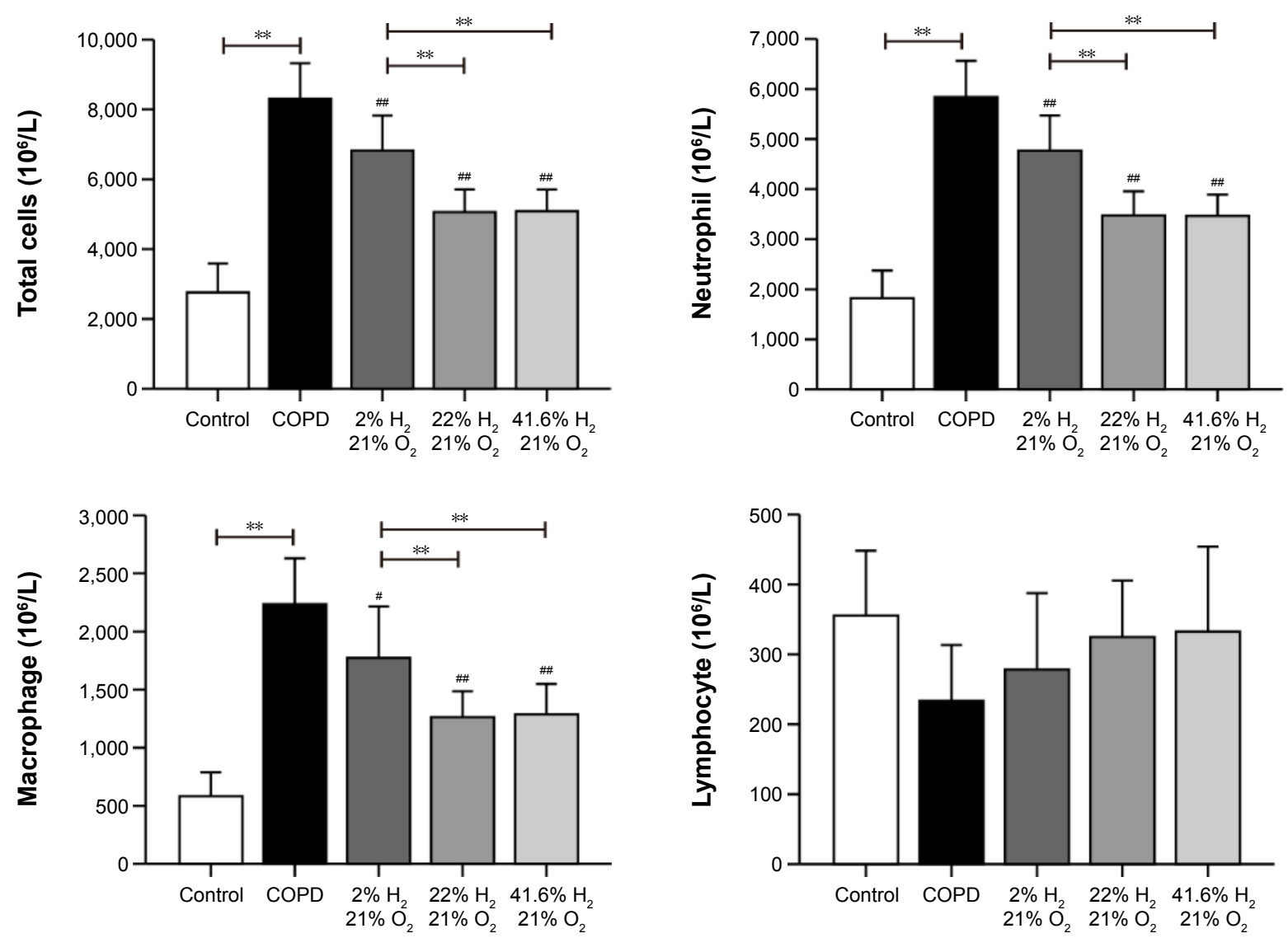

Figure 2 Impact of hydrogen on inflammatory cells in rats with COPD-like lung disease.

Notes: The inflammatory cells in BALF were measured to compare the effect of hydrogen in rats with COPD-like lung disease. ( $\mathrm{n}=10$ for each group; ${ }^{\#}<<0.05$, \#P<0.01 compared with COPD group; $* * P<0.01)$.

Abbreviations: BALF, bronchoalveolar lavage fluid; COPD, chronic obstructive pulmonary disease.

\section{Hydrogen coadministration ameliorates pathologic changes of lung in a cigarette smoke-induced rat model}

Compared with the control group, the lung volume in the COPD group was increased; on gross morphology, it was white and uneven, rather than smooth, and had poor flexibility. The alveolar ducts, alveolar sacs, and pulmonary alveoli of rats in the COPD group were significantly expanded; the alveoli were structurally disordered, the alveolar wall showed signs of thinning and breaking, and some had fused into bullae. The ciliated cells showed degeneration and necrosis. The pulmonary artery wall was thickened, and the lumen narrowed, with varying degrees of peripheral neutrophil, lymphocyte, and mononuclear macrophage infiltration. The lungs in rats of the $\mathrm{Hl}, \mathrm{Hm}$, and $\mathrm{Hh}$ groups were slightly reduced compared to those of rats in the COPD group, and the appearance of the lungs was also improved. The pulmonary artery walls showed mild thickening; the alveolar wall was relatively thin, inflammatory cells were decreased, and the fracture conditions were improved, compared with those in the COPD group (Figure 3A).
Compared with the control group, the mean linear interval and BWT/D in the COPD group were significantly increased $(P<0.01)$, and the MAN was significantly reduced $(P<0.01)$. Compared with the COPD group, these were reduced, but MAN was increased in the $\mathrm{Hl}, \mathrm{Hm}$, and $\mathrm{Hh}$ groups (Figure 3B). These results suggest that hydrogen coadministration ameliorates the pathologic changes of lung in a cigarette smoke-induced rat model.

\section{Hydrogen coadministration ameliorates ultrastructural changes of lung in a cigarette smoke-induced rat model}

SEM observations showed alveolar septa with a smooth surface with no fracture in the control group. The alveolar wall showed structural integrity; also, the alveolar epithelial cells were arranged in an orderly manner with clear boundaries. The alveoli were well inflated; there was no alveolar hemorrhage, exudation, or inflammatory cell infiltration present. Compared with the control group, the alveolar septum in the COPD group was thinner and showed subsequent fracture. The structural integrity of the alveolar 
A

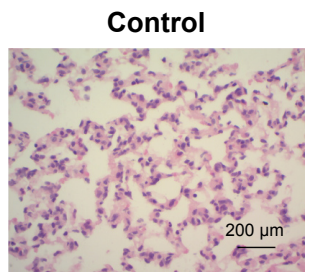

COPD

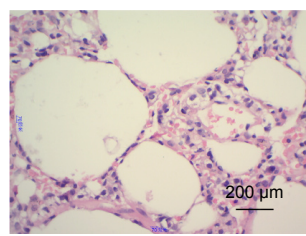

$2 \% \mathrm{H}_{2}, 21 \% \mathrm{O}_{2}$

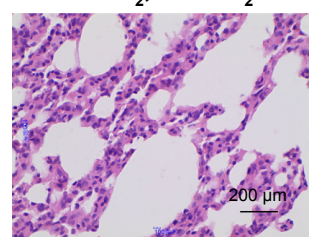

$22 \% \mathrm{H}_{2}, 21 \% \mathrm{O}_{2}$

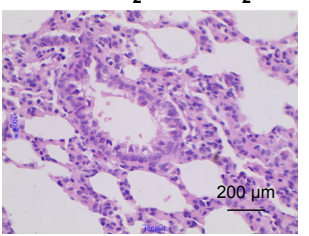

$41.6 \% \mathrm{H}_{2}, 21 \% \mathrm{O}_{2}$

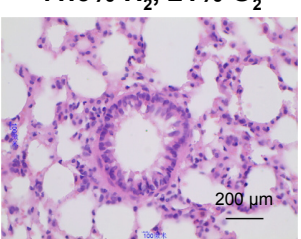

B
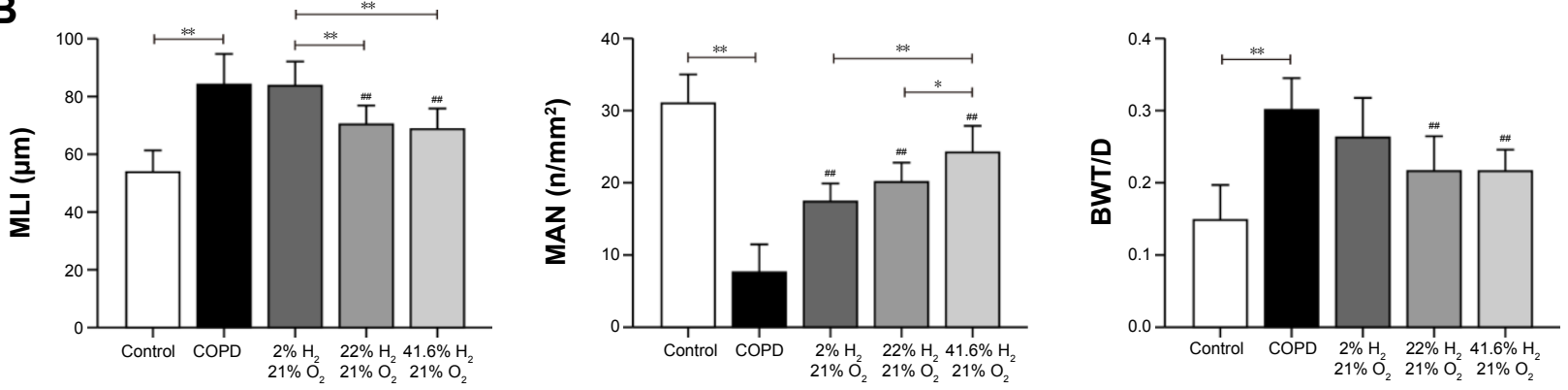

Figure 3 Effect of hydrogen on the pathologic lung changes in rats with COPD-like lung disease

Notes: (A) Rat lung pathologic observations (HE $\times 400)$. (B) MLI, MAN, and BWT/D were measured to compare the effect of hydrogen in rats with COPD-like lung disease. ( $n=10$ for each group. $P<0.01$ compared with the COPD group, $* P<0.05, * * P<0.01$ ).

Abbreviations: BWT/D, bronchial wall thickness/diameter; COPD, chronic obstructive pulmonary disease; HE, hematoxylin and eosin; MAN, mean alveolar number; MLI, mean linear intercept.

wall was damaged, and the alveolar epithelial cells were disorganized. Alveolar hyperinflation occurred, and lymphocytes and cell shed debris were present in the alveoli. The alveolar septum was thinner, occasionally ruptured, and a small amount of inflammatory cells in the Hl group. The alveolar septum showed a smooth surface in the Hm and Hh groups, and no fracture was present. The alveolar wall showed structural integrity and the alveolar epithelial cells were arranged in an orderly manner. There was no alveolar bleeding or exudation, and only occasional inflammatory cell infiltration was seen. Thus, the alveolar condition was improved in the $\mathrm{Hm}$ and $\mathrm{Hh}$ groups, compared to the $\mathrm{Hl}$ group (Figure 4A).

The ultrastructural changes of alveolar type II epithelial cells were also observed under TEM for each group. The microvilli on the surface of alveolar type II epithelial cells
A

A Control

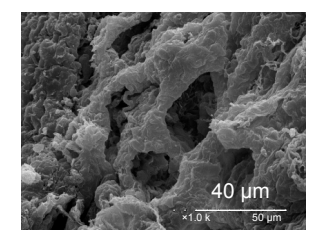

B

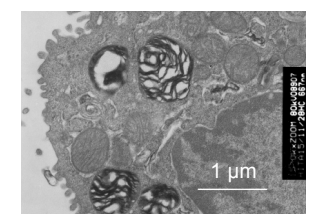

C Control

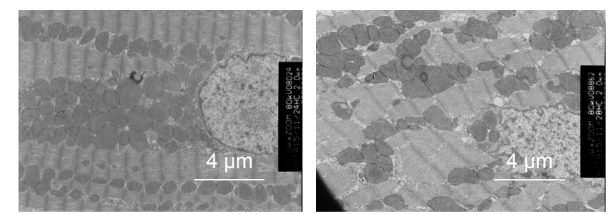

COPD

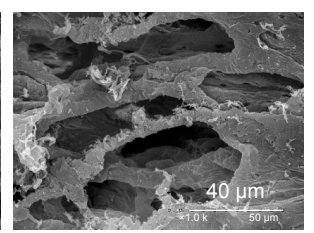

COPD

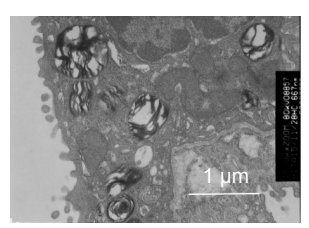

COPD

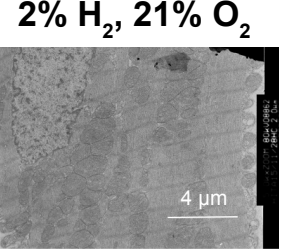

$2 \% \mathrm{H}_{2}, 21 \% \mathrm{O}_{2}$

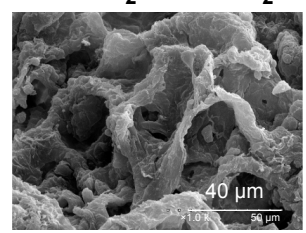

$2 \% \mathrm{H}_{2}, 21 \% \mathrm{O}_{2}$

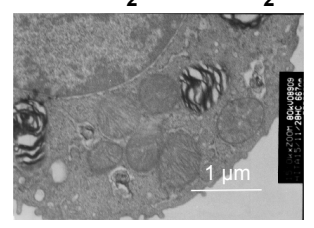

$22 \% \mathrm{H}_{2}, 21 \% \mathrm{O}_{2}$

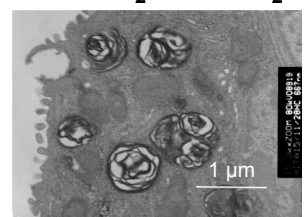

$22 \% \mathrm{H}_{2}, 21 \% \mathrm{O}_{2}$

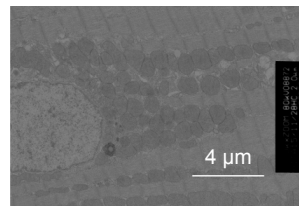

$41.6 \% \mathrm{H}_{2}, 21 \% \mathrm{O}_{2}$
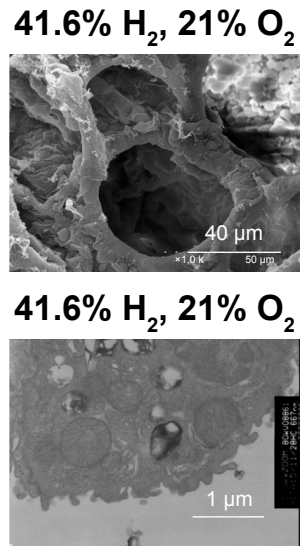

$41.6 \% \mathrm{H}_{2}, 21 \% \mathrm{O}_{2}$

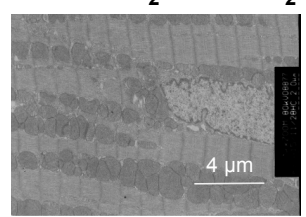

Figure 4 Effect of hydrogen on changes in the ultrastructure of COPD-like lung disease rats.

Notes: (A) Lung tissue observation of five groups under SEM. (B) Lung tissue observation of five groups under TEM. (C) Cardiac tissue observation of five groups under TEM.

Abbreviations: COPD, chronic obstructive pulmonary disease; SEM, scanning electron microscope; TEM, transmission electron microscope. 
were uncompromised in the control group, the cristae and membrane of mitochondria showed a clear structure, the rough endoplasmic reticulum was regular in structure, and the nucleus had clear boundaries. Compared with the control group, the microvilli on the surface of alveolar type II epithelial cells were reduced in the COPD group, the cristae and membrane of the mitochondria were markedly fused, and giant mitochondria were visible. The rough endoplasmic reticulum was expanded and the perinuclear gap was widened. However, in the $\mathrm{Hl}, \mathrm{Hm}$, and Hh groups, these showed significant improvement (Figure 4B).

The ultrastructural changes of the myocardial cells were also observed under TEM in each group. In the control group, the sarcomere had an orderly arrangement, the nucleus had clear boundaries, and the mitochondrial cristae and membrane had a clear structure. Compared with the control group, the sarcomere arrangement was disorganized in the COPD group, and the perinuclear gap in the cardiomyocytes was widened. The cristae and membrane of their mitochondria showed signs of fusion; giant mitochondria were visible, and some mitochondria had herniated. Compared with the COPD group, the sarcomere arrangement was orderly in the $\mathrm{Hl}, \mathrm{Hm}$, and $\mathrm{Hh}$ groups; the perinuclear gap was widened slightly, whereas the mitochondria showed slight edema and mild fusion (Figure 4C).

\section{Hydrogen coadministration ameliorates mPAP, LVEF, RVAWd, and LVAWd}

The mPAP was significantly higher in the COPD group $(P<0.01)$ and significantly lower in each hydrogen inhalation group $(P<0.01)$, compared to the control group; this value was also lower in the Hm group than in the $\mathrm{Hl}$ and $\mathrm{Hh}$ groups $(P<0.05)$. The LVEF in the COPD group was significantly lesser than that in the control group $(P<0.01)$; compared to the COPD group, the LVEF in the $\mathrm{Hl}$ group was reduced $(P<0.05)$, but there were no differences in the LVEF in the $\mathrm{Hm}$ and $\mathrm{Hh}$ groups. LVEF in the $\mathrm{Hl}$ group was significantly lesser than in the $\mathrm{Hm}(P<0.05)$ and Hh groups $(P<0.01)$. The RVAWd in the COPD group was significantly greater than that in the control group $(P<0.01)$; compared with the COPD group, a significant decrease was seen in each hydrogen inhalation group (all $P<0.01$ ), but there was no significant difference among the hydrogen inhalation groups. There was no significant difference in the end-diastolic left ventricular anterior wall thickness between the COPD group and the control group; compared to the COPD group, there was no difference in each of the hydrogen inhalation groups. There was also no difference in LVPWd between the COPD group and the control group; a significant decrease was seen in this value for the Hl group $(P<0.01)$, but not for the Hm or Hh group compared to the control group. LVPWd in the $\mathrm{Hl}$ group was also smaller than that in the Hm group $(P<0.05$; Figure 5).

\section{Hydrogen coadministration reduces RVHI in a cigarette smoke-induced rat model}

The RVHI in the COPD group was significantly increased than that in the control group $(P<0.01)$. Compared with the COPD group, the RVHI in each hydrogen inhalation group was significantly reduced (all $P<0.01$ ); the values in the $\mathrm{Hm}$ and Hh groups were also lower than that in the $\mathrm{Hl}$ group $(P<0.01$; Figure 5). These results suggest that hydrogen coadministration reduces RVHI in a cigarette smoke-induced rat model.

\section{Hydrogen coadministration reduces the mRNA and protein expression of TNF- $\alpha$, IL-6, IL- I7, IL-23, MMP-I2, caspase-3, and caspase-8, but increases TIMP- I expression}

Expression of proteins such as TNF- $\alpha$, IL-6, IL-17, IL-23, MMP-12, TIMP-1, caspase-3, and caspase-8 (IHC, Figures 6 and 7; WB, Figure 8) was detected by IHC and WB of the lung tissue. Expression of TNF- $\alpha$, IL-6, IL-17, IL-23, MMP-12, TIMP-1, caspase-3, and caspase- 8 was visible in the bronchi of all sizes, as well as in the cytoplasm of the alveolar infiltrated inflammatory cells. Compared with the control group, the expression levels of all these proteins were increased in the COPD group. The expression levels of TNF- $\alpha$, IL-6, IL-17, IL-23, MMP-12, caspase-3, and caspase- 8 were reduced; however, the expression level of TIMP-1 was increased in each of the hydrogen inhalation groups, compared with the COPD group. There was no significant difference in the expression levels of these proteins between the Hm group and the Hh group, but except for TIMP-1, the expression levels in both groups were lower than that in the $\mathrm{Hl}$ group. These results suggest that hydrogen coadministration reduces the protein expression levels of TNF- $\alpha$, IL-6, IL-17, IL-23, MMP-12, caspase-3, and caspase-8, but increases TIMP-1 expression.

Gene expression of TNF- $\alpha$, IL-6, IL-17, IL-23, MMP-12, TIMP-1, caspase-3, and caspase-8 (Figure 9) in the lung was assessed by RT-PCR. In the COPD group, the mRNA expression levels of genes encoding TNF- $\alpha$, IL-6, IL-17, IL-23, MMP-12, TIMP-1, caspase-3, and caspase-8 were significantly increased, compared with those in the control group $(P<0.01)$. Compared with the COPD group, the gene 

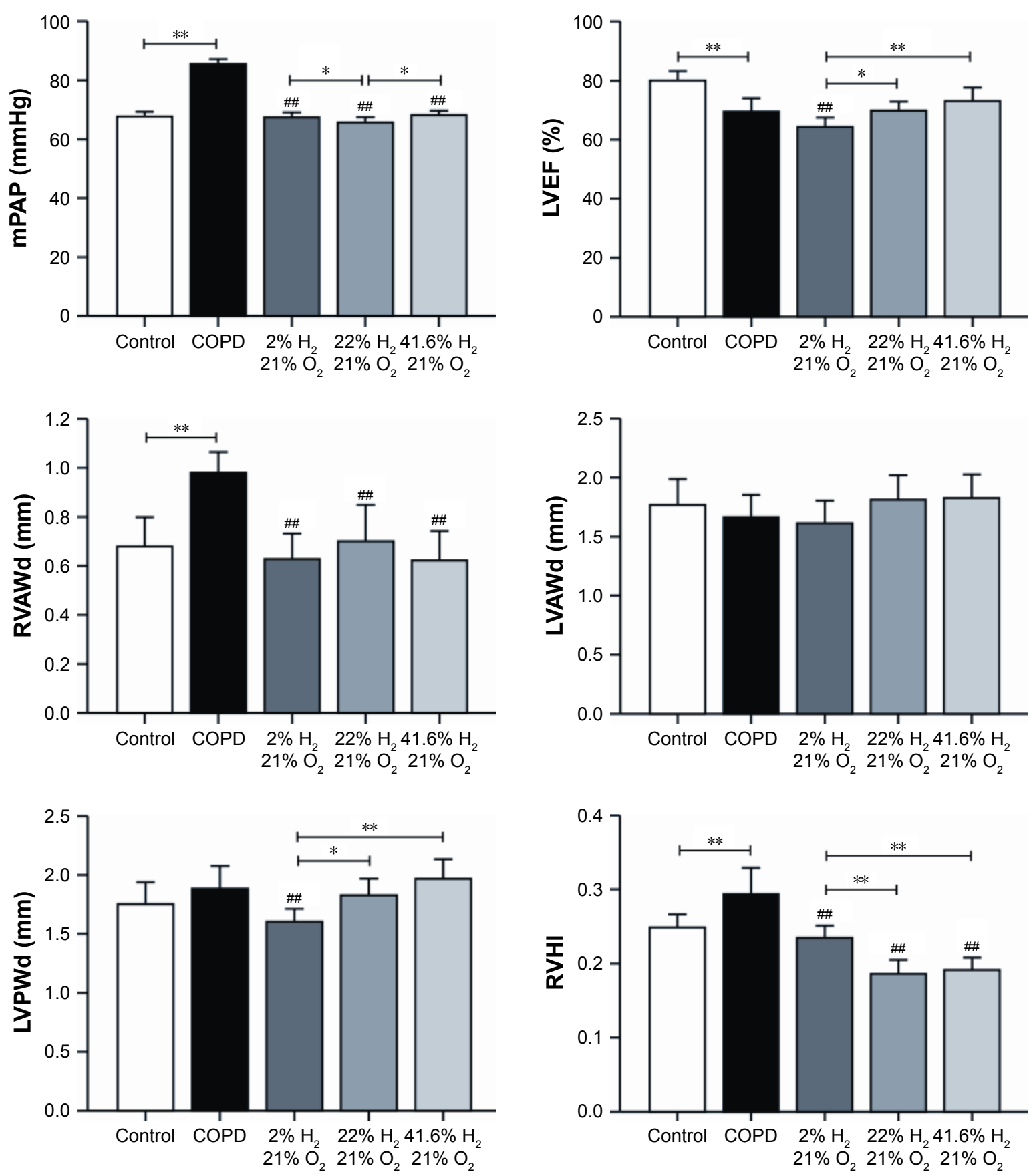

Figure 5 Changes in cardiovascular indices and RVHI after hydrogen coadministration to COPD-like lung disease rats.

Notes: Comparisons of mPAP, LVEF, RVAWd, LVAWd, LVPWd, and RVHI. ( $\mathrm{n}=10$ for each group; ${ }^{*} \mathrm{P}<0.01$ compared with COPD group, $* P<0.05$, $* * P<0.01$ ).

Abbreviations: COPD, chronic obstructive pulmonary disease; LVAWd, end-diastolic left ventricular anterior wall thickness; LVEF, left ventricular ejection fraction; LVPWd, end-diastolic left ventricular posterior wall thickness; mPAP, mean pulmonary arterial pressure; RVAWd, end-diastolic right ventricular anterior wall thickness; RVHI, right ventricular hypertrophy index.

expression levels of TNF- $\alpha$, IL-6, IL-17, and IL-23 were decreased in all hydrogen inhalation groups $(P<0.01$ or $P<0.05)$; there was no significant difference in the expression of these genes between the Hm group and the Hh group, both of which were lower than that in the Hl group $(P<0.01$ or $P<0.05$ ). Compared with the COPD group, the mRNA expression levels of MMP-12, caspase-3, and caspase- 8 were significantly decreased in all hydrogen inhalation groups (all $P<0.01$ ); no significant differences were found among the hydrogen inhalation groups. The mRNA expression level of TIMP-1 was significantly increased in the Hm and Hh groups $(P<0.01)$, and in the Hl group $(P<0.05)$, compared with the COPD group; no significant difference was found between the Hm group and the Hh group. These results suggest that 
A Control
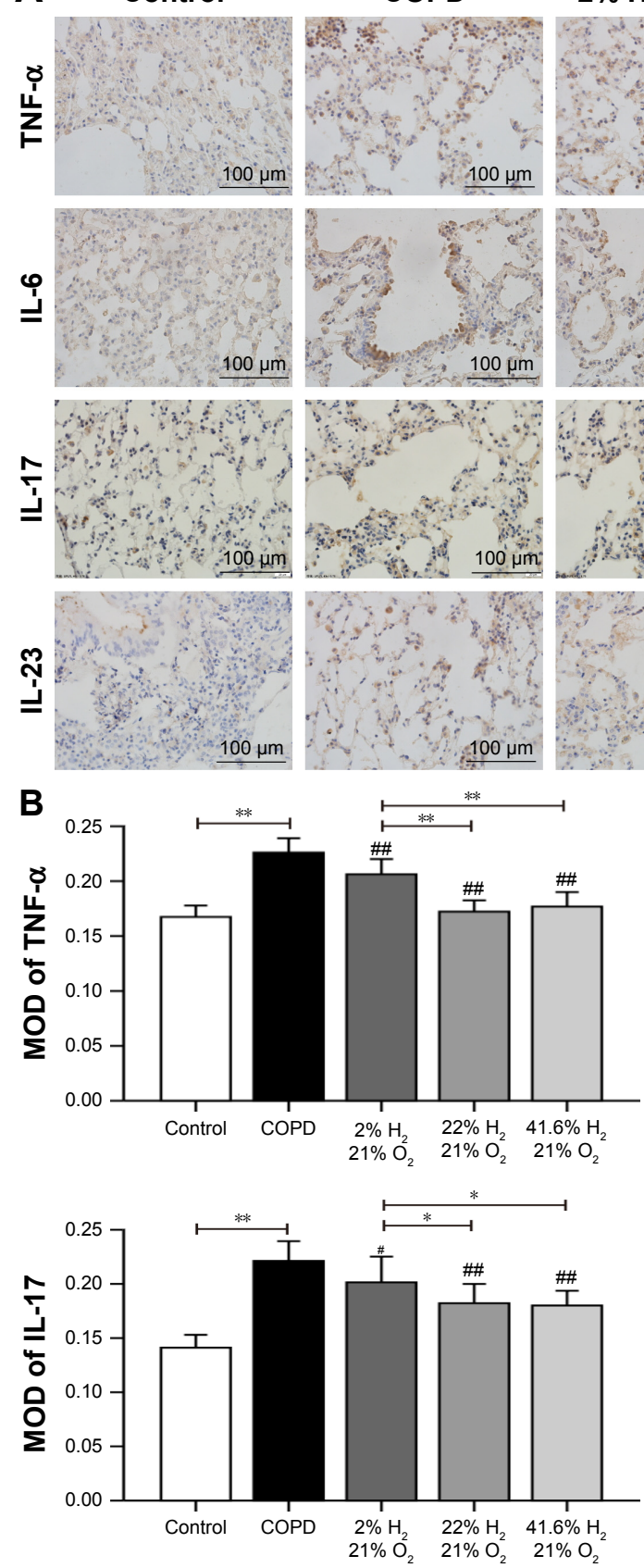

$2 \% \mathrm{H}_{2}, 21 \% \mathrm{O}_{2}$

$22 \% \mathrm{H}_{2}, 21 \% \mathrm{O}_{2}$

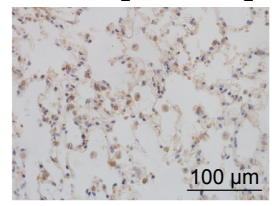

$41.6 \% \mathrm{H}_{2}, 21 \% \mathrm{O}_{2}$
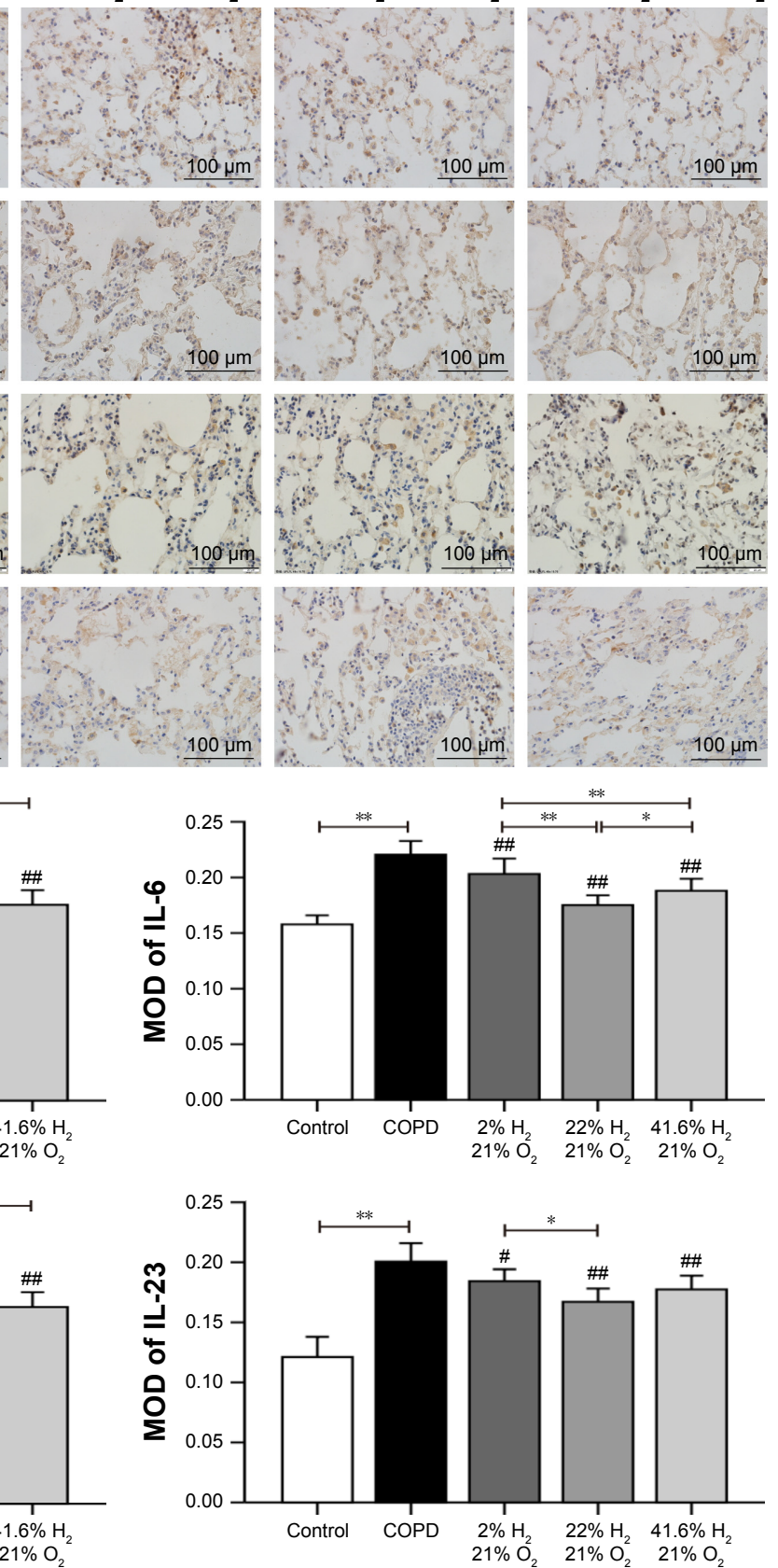

Figure 6 Effect of hydrogen on the expression of TNF- $\alpha$, IL-6, IL-I7, and IL-23 in the lung obtained from COPD-like lung disease rats, found by immunohistochemical staining.

Notes: (A) Immunohistochemical staining of the lung sections for TNF- $\alpha$, IL-6, IL-I7, and IL-23. (B) Quantitative analysis of the expression of TNF- $\alpha$, IL-6, IL- I7, and IL-23 in the lung of COPD-like lung disease rats. ( $n=10$ for each group. ${ }^{*}<<0.05 ;{ }^{\#} P<0.01$ compared with COPD group. $* P<0.05$; $* * P<0.01$ ). Each experiment was repeated three times and similar results were obtained.

Abbreviations: COPD, chronic obstructive pulmonary disease; IL, interleukin; MOD, mean optical density; TNF- $\alpha$, tumor necrosis factor alpha.

hydrogen coadministration reduces the mRNA expression levels of TNF- $\alpha$, IL-6, IL-17, IL-23, MMP-12, caspase-3, and caspase-8, but increases TIMP-1 expression.

\section{Discussion}

COPD is a common respiratory disease showing an annual increase in morbidity and mortality rates, which is associated with inflammation, protease/antiprotease system imbalance, and apoptosis. ${ }^{10,11}$

In this study, cigarette smoke exposure was used to establish COPD-like lung disease model in rats. These rats exhibited typical pathologic changes of COPD that were accompanied with decreased lung function. It was found that $2 \%, 22 \%$, and $41.6 \%$ hydrogen improved the 


\section{A Control}
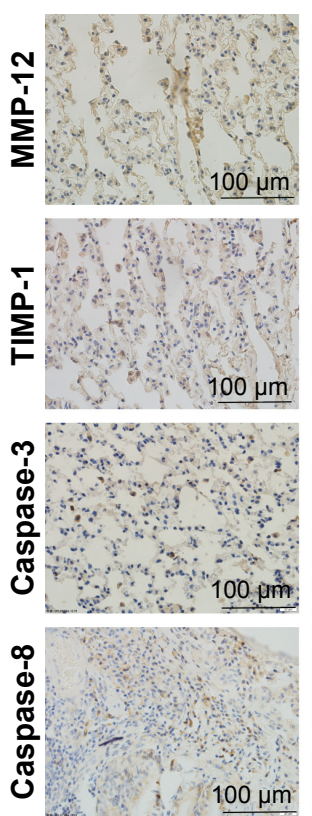

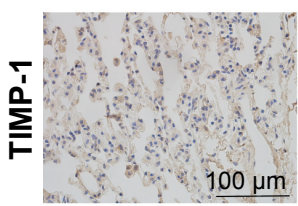

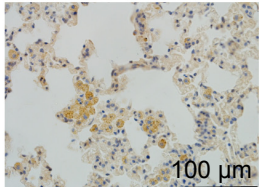

$2 \% \mathrm{H}_{2}, 21 \% \mathrm{O}_{2}$
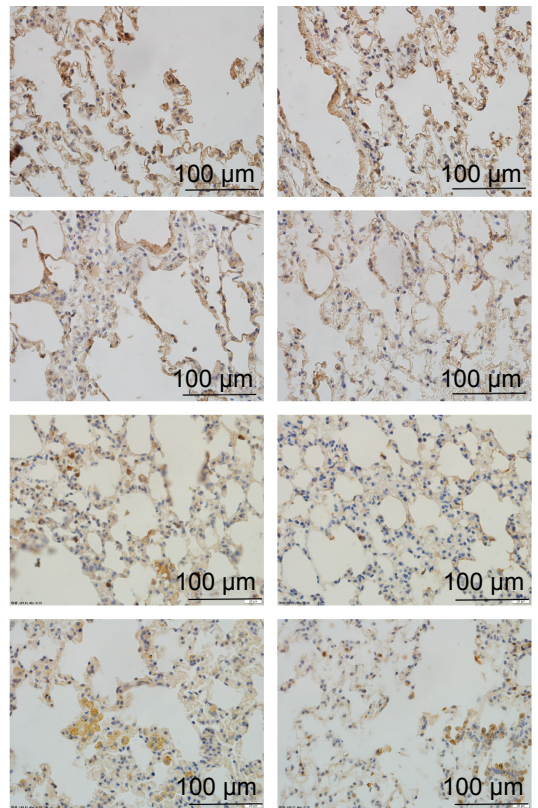

$22 \% \mathrm{H}_{2}, 21 \% \mathrm{O}_{2} \quad 41.6 \% \mathrm{H}_{2}, 21 \% \mathrm{O}_{2}$
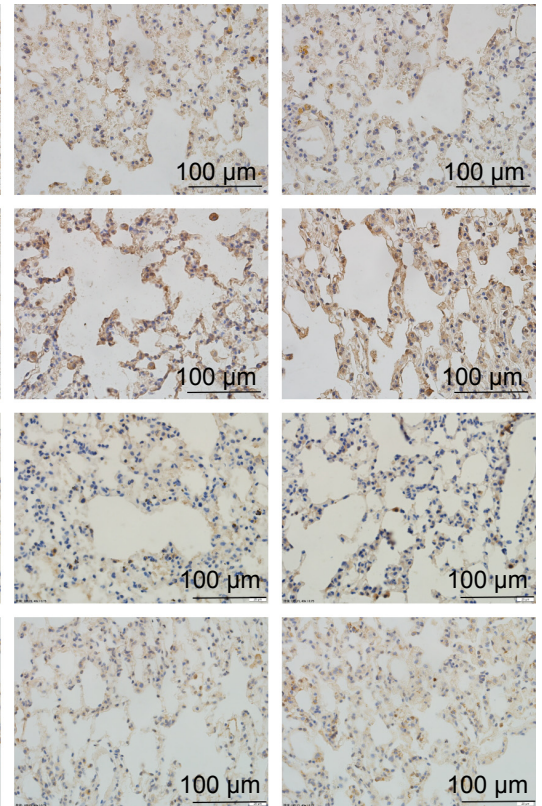

$100 \mu \mathrm{m}$
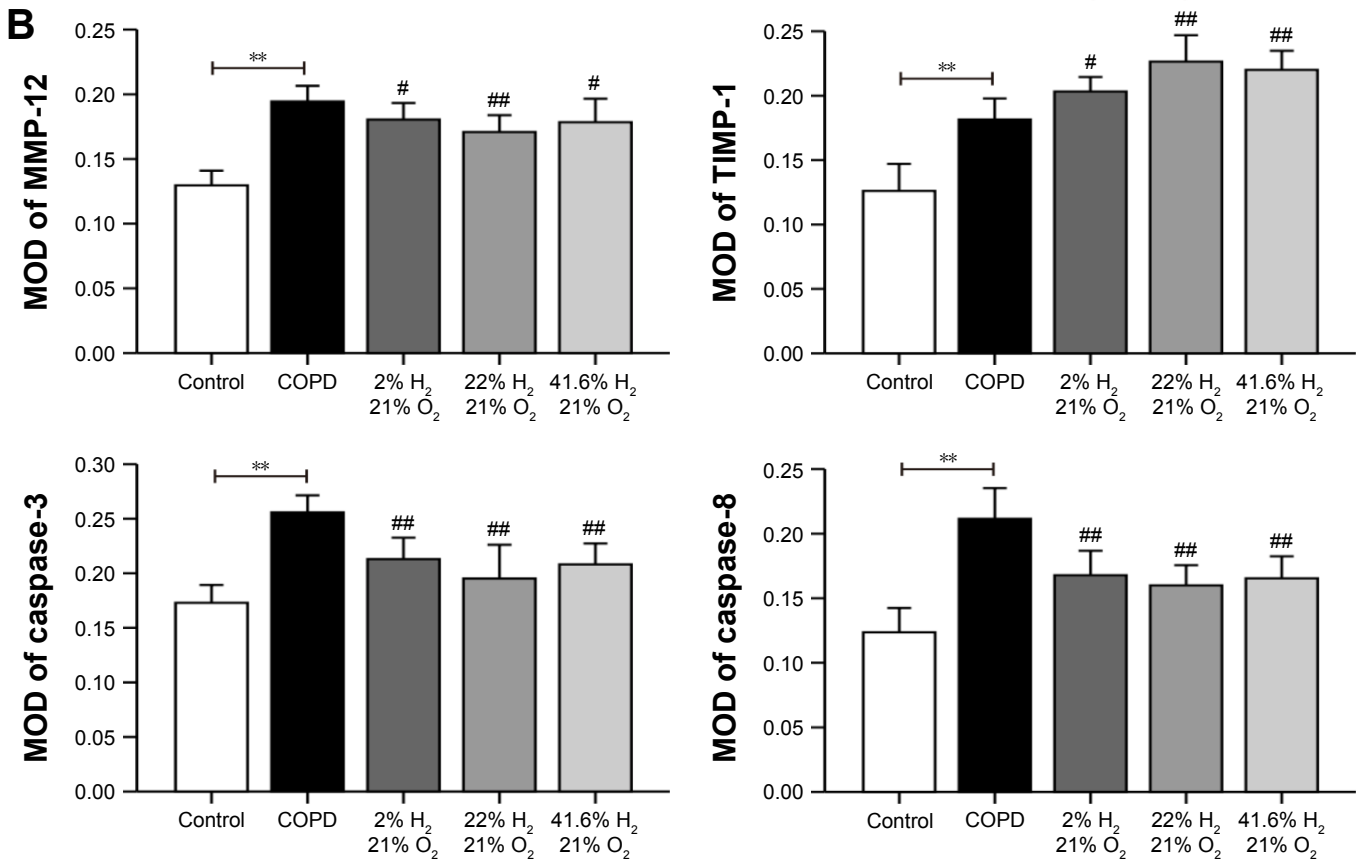

Figure 7 Effect of hydrogen on the expression of MMP-I2, TIMP-I, caspase-3, and caspase-8 in the lung obtained from COPD-like lung disease rats, found by immunohistochemical staining.

Notes: (A) Immunohistochemical staining of the lung sections for MMP-I2, TIMP-I, caspase-3, and caspase-8. (B) Quantitative analysis of the expression of MMP-I2, TIMP-I, caspase-3, and caspase-8 in the lung of COPD-like lung disease rats. ( $n=10$ for each group; ${ }^{P}<0.05,{ }^{\# P}<0.01$ compared with $C O P D$ group; $* P<0.05, * * P<0.01$ ). Each experiment was repeated three times and similar results were obtained.

Abbreviations: COPD, chronic obstructive pulmonary disease; MMP, matrix metalloproteinase; MOD, mean optical density; TIMP, tissue inhibitor of metalloproteinase.

lung pathology and function through inhibition of pulmonary inflammatory cytokines and apoptotic proteins and restoration of protease/antiprotease balance; $22 \%$ and $41.6 \%$ hydrogen showed enhanced beneficial effects over $2 \%$ hydrogen.
Alveolar septum rupture, alveolar tissue-unrelated discharge, and cell residue under SEM have been reported in an emphysema model generated in Wistar rats. ${ }^{29}$ In the COPDlike lung disease model generated in this study, marked damage was also found in alveolar septa, alveolar walls, and 
A

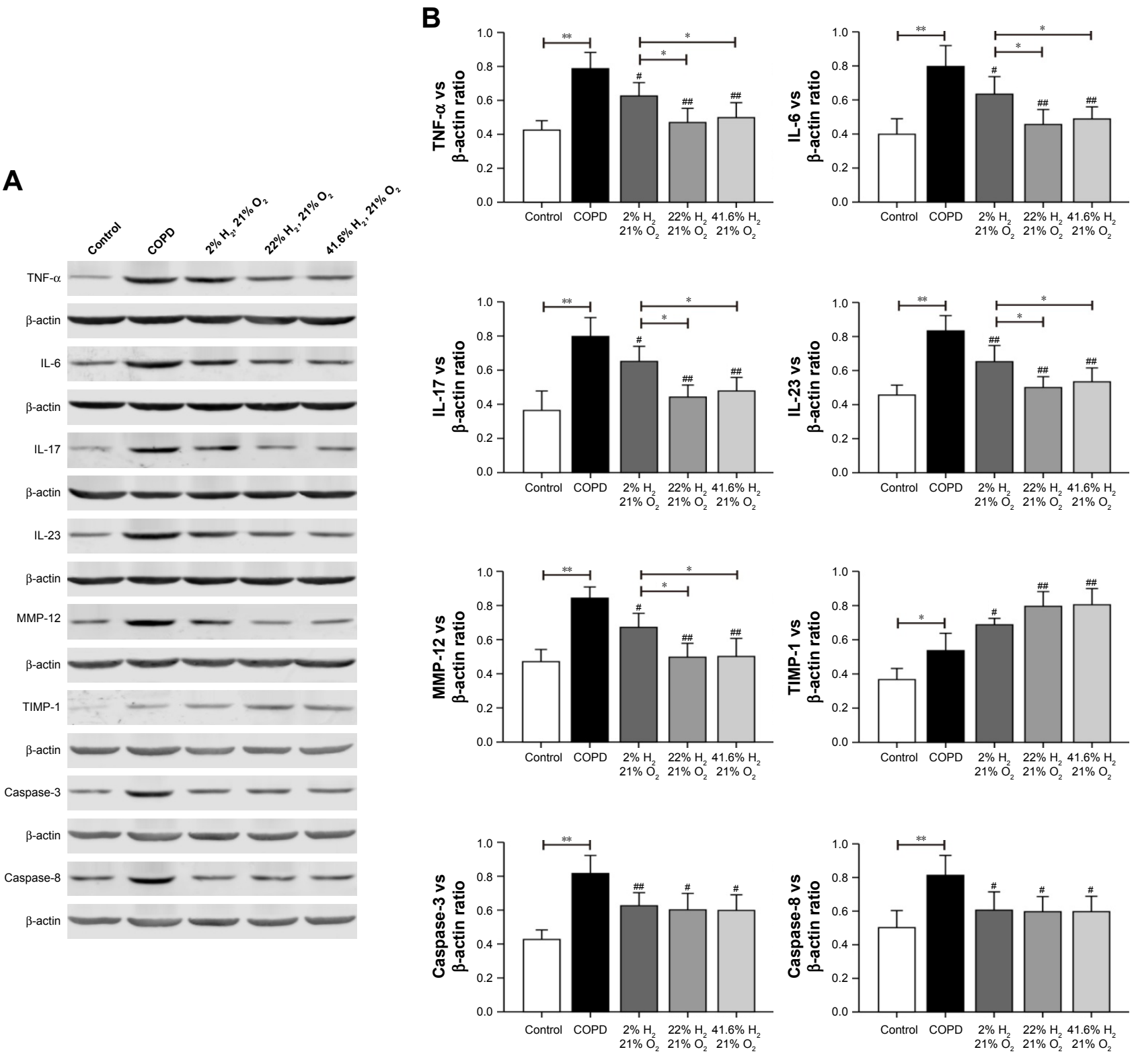

Figure 8 Effect of hydrogen on the expression of TNF- $\alpha$, IL-6, IL-I7, IL-23, MMP-I2, TIMP-I, caspase-3, and caspase- 8 in the lung obtained from COPD-like lung disease rats, determined by Western blotting.

Notes: (A) Western blotting of the lung sections for TNF- $\alpha$, IL-6, IL- I7, IL-23, MMP- I2, TIMP-I, caspase-3, and caspase-8. (B) The target protein bands were densitometrically analyzed normalized to $\beta$-actin. ( ${ }^{*} P<0.05,{ }^{*} P<0.01$ compared with COPD group; ${ }^{*} P<0.05,{ }^{* *} P<0.01$ ). Each experiment was repeated three times and similar results were obtained.

Abbreviations: COPD, chronic obstructive pulmonary disease; IL, interleukin; MMP, matrix metalloproteinase; TIMP, tissue inhibitor of metalloproteinase; TNF- $\alpha$, tumor necrosis factor alpha.

alveolar epithelial cells. Alveolar structure was improved to some extent in each of the hydrogen inhalation groups. Recent studies demonstrated that the ultrastructure of intestinal epithelial cells was improved in Wistar rats with septic shock after inhalation of $2 \%$ hydrogen; ${ }^{30}$ hydrogen also had a protective effect on hyperoxia-induced alveolar type II epithelial cell damage. ${ }^{31}$ In this study, we found that the ultrastructure of alveolar type II epithelial cells was improved in each of the hydrogen inhalation groups. Ohsawa et al discovered that hydrogen could pass through biologic membranes and diffuse into the cytoplasm, mitochondria, and nucleus. ${ }^{16}$ In this study, the cristae of myocardial mitochondria were not clear in the COPD group and appeared fractured or absent. The myocardial mitochondrial structure was improved in each of the hydrogen inhalation groups, which further confirmed that hydrogen has a protective effect on mitochondria. ${ }^{32}$ Moreover, among the three concentrations of hydrogen used in this study, $41.6 \%$ hydrogen possessed the optimal effect.

The expression levels of TNF- $\alpha$ and IL- 6 have been shown to increase in the lungs of individuals with COPD..$^{5-7}$ The 
expression of IL-17 in bronchial tissues increases in patients with COPD. ${ }^{33}$ IL-23 could induce T-helper cell 17 (Th17) differentiation and release of TNF- $\alpha$, IL- 6 , and IL-17,,34,35 whereas IL-17 could also induce TNF- $\alpha$ and IL-6 expression.
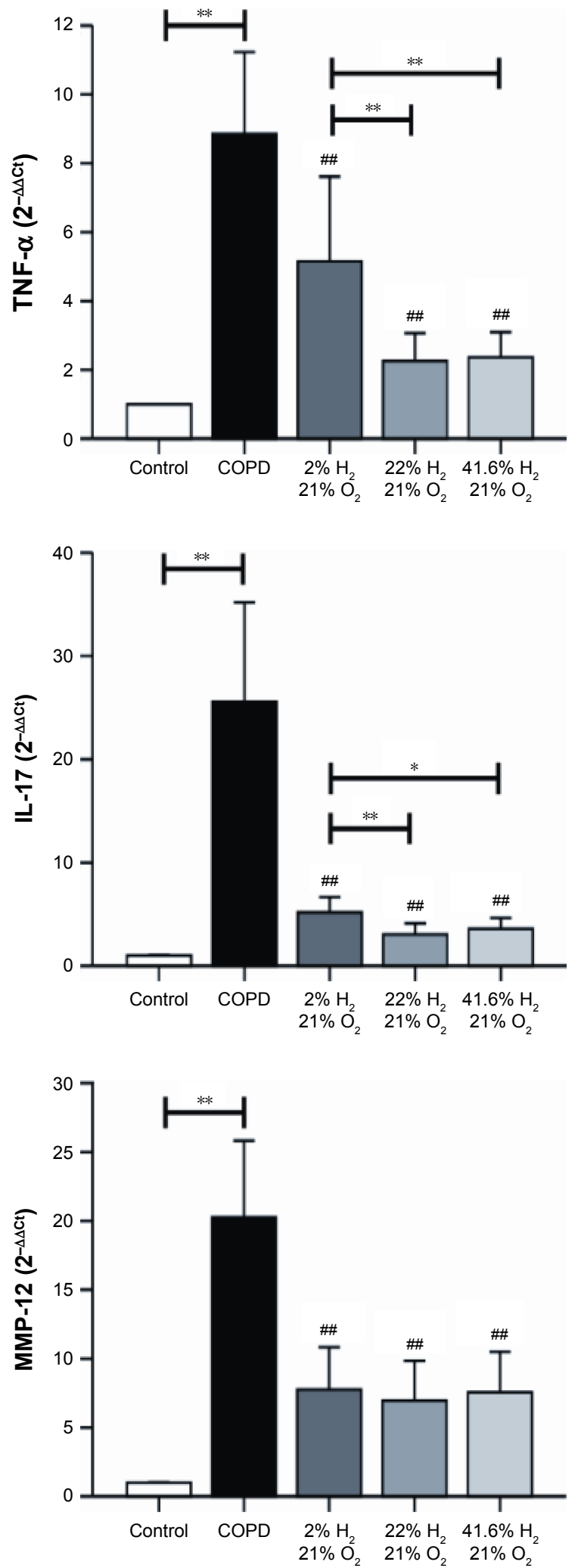

Figure 9 (Continued)
Qiu et al found that $2 \%$ hydrogen could alleviate acute lung injury by reducing TNF- $\alpha$ and IL-6 expression..$^{36}$ This study showed that hydrogen could reduce the number of inflammatory cells in the BALF and reduce the expression of TNF- $\alpha$,
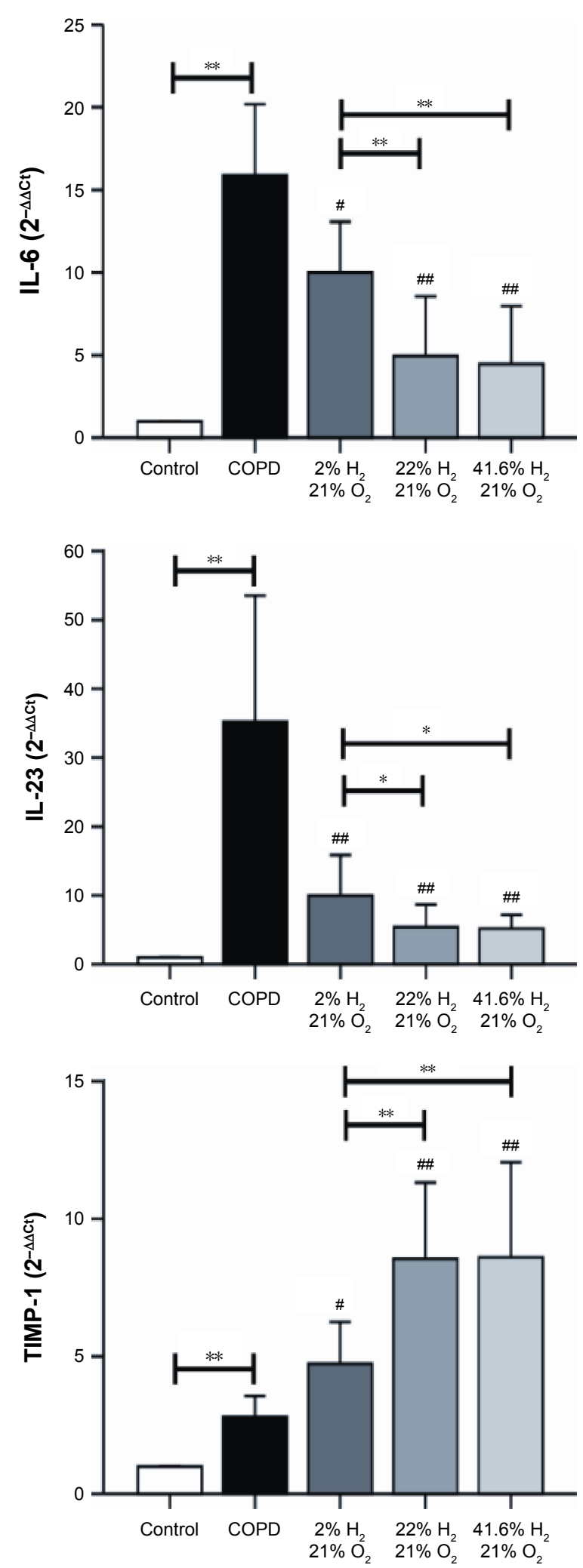

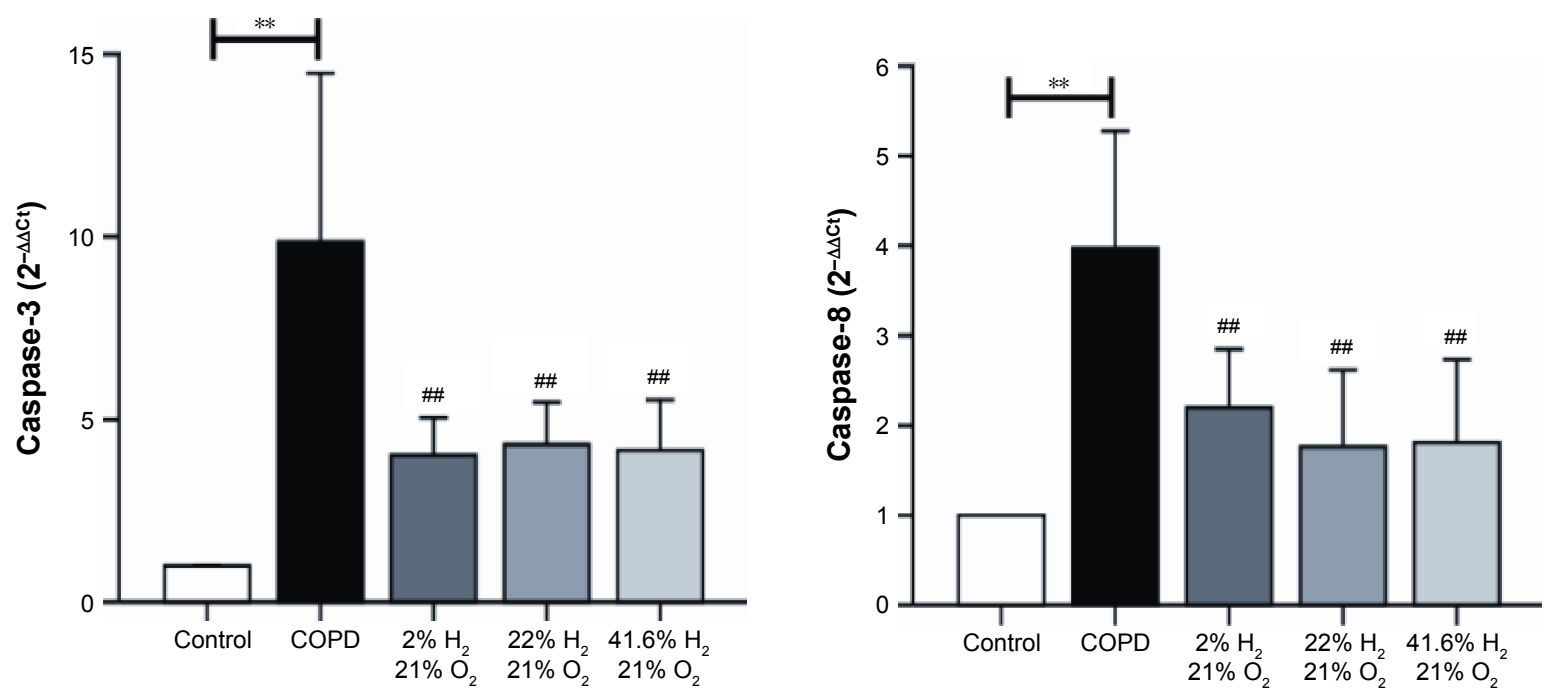

Figure 9 Effect of hydrogen on the mRNA expression of TNF- $\alpha$, IL-6, IL-17, IL-23, MMP-I2, TIMP-I, caspase-3, and caspase-8 in the lung obtained from COPD-like lung disease rats, analyzed by RT-PCR.

Notes: The mRNA levels of TNF- $\alpha$, IL-6, IL- I7, IL-23, MMP-12, TIMP-I, caspase-3, and caspase-8 were analyzed with RT-PCR. ( $\mathrm{n}=10$ for each group; ${ }^{\# P<0.05, ~ \# P<0.01}$ compared with COPD group; $* P<0.05, * * P<0.01)$.

Abbreviations: COPD, chronic obstructive pulmonary disease; IL, interleukin; MMP, matrix metalloproteinase; mRNA, messenger RNA; RT-PCR, real-time polymerase chain reaction; TIMP, tissue inhibitor of metalloproteinase; TNF- $\alpha$, tumor necrosis factor alpha.

IL-6, IL-17, and IL-23; in this respect, $22 \%$ and $41.6 \%$ hydrogen yielded better outcome than $2 \%$ hydrogen. These results suggest that hydrogen inhalation alleviated inflammation through its inhibitory actions on the number of inflammatory cells, the expression of inflammatory factors, or both.

A protease/antiprotease imbalance plays an important role in the pathogenesis of COPD, and the adverse effect of imbalance of MMP-12/TIMP-1 in COPD has been demonstrated. ${ }^{8,9}$ It has not been reported to date whether hydrogen can affect the protease/antiprotease balance in the lungs with COPD. This study showed that hydrogen could reduce the expression of MMP-12 and increase the expression of TIMP-1, thereby restoring the balance of MMP-12/TIMP-1; in this respect, $22 \%$ and $41.6 \%$ hydrogen were again more effective than $2 \%$ hydrogen. It has been shown that there is an association between proteases and inflammatory cytokines; inflammatory cytokines release proteases by excessive recruitment of inflammatory cells, ${ }^{37}$ aggravating tissue inflammation and causing the release of more inflammatory cytokines. It is likely that hydrogen can affect the protease/antiprotease balance by reducing the expression of inflammatory cytokines.

Apoptosis plays an important role in the development of COPD. Previous studies have shown that an increase in protease levels could induce apoptosis in lung parenchymal cells. ${ }^{38}$ Huang et al found that $2 \%$ hydrogen could alleviate lung injuries through reducing the expression of caspase-3 and increasing the expression of B-cell lymphoma-xl, ${ }^{39}$ whereas Kawamura et al found that 2\% hydrogen could alleviate lung transplantation damage through reducing the expression of Bcl-2 Associated X protein and increasing the expression of B-cell lymphoma-2. ${ }^{40}$ This study demonstrated that hydrogen could reduce apoptosis in COPD by reducing the expression levels of caspase- 3 and caspase- 8 , with $22 \%$ and $41.6 \%$ hydrogen performing better than $2 \%$ hydrogen, although there was no difference between the effects of $22 \%$ and $41.6 \%$ hydrogen.

There is no influence of hydrogen on the physiologic properties, such as temperature, blood pressure, blood $\mathrm{pH}$, and $\mathrm{PaO} 2 .{ }^{16}$ The use of a low concentration of hydrogen in clinical treatment is for the safety of vessel hemodynamic indexes, such as heart rate and left ventricular pressure. ${ }^{41}$ Additionally, we have not found any abnormal condition with regard to the anatomy and pathology of all our rat models. Although there is no report about hydrogen's adverse effect, we should pay attention to the safety aspects when there is an accident, such as firing or bombing, though it is a very rare event. In summary, inhalation of hydrogen can significantly reduce the level of inflammation and apoptosis, restore the protease/antiprotease balance, protect mitochondria, and ameliorate the pathologic structure of lung tissue, lung function, and cardiovascular function in a rat model. Thus, this intervention may slow the development of COPD; especially intermediate and high concentrations of hydrogen are more efficacious than low concentrations. There may still be many unknown medical applications of hydrogen, warranting 
further basic and clinical studies; also, future studies should be conducted in human patients.

\section{Acknowledgments}

We are very grateful to the Laboratory of Forensic Medicine of Hebei Medical University for its support. We thank Ning Guo (Harvard Medical School, Boston, MA, USA) for advice on experimental design.

\section{Disclosure}

The authors report no conflicts of interest in this work.

\section{References}

1. Pauwels RA, Buist AS, Calverley PM, et al. Global strategy for the diagnosis, management, and prevention of chronic obstructive pulmonary disease. Am J Respir Crit Care Med Apr. 2001;163:1256-1276.

2. Redington AE, Howarth PH. Airway wall remodelling in asthma. Thorax. 1997;52(4):310-312.

3. Vestbo J, Hurd SS, Agustí AG, et al. Global strategy for the diagnosis, management, and prevention of chronic obstructive pulmonary disease: GOLD executive summary. Am J Respir Crit Care Med. 2013; 187:347-365.

4. Eisner MD, Anthonisen N, Coultas D, et al. An official American Thoracic Society public policy statement: novel risk factors and the global burden of chronic obstructive pulmonary disease. Am J Respir Crit Care Med. 2010;182(5):693-718.

5. Amrani Y, Panettieri RA Jr, Frossard N, Bronner C. Activation of the TNF alpha-p55 receptor induces myocyte proliferation and modulates agonist-evoked calcium transients in cultured human tracheal smooth muscle cells. Am J Respir Cell Mol Biol. 1996;15(1):55-63.

6. Barczyk A, Pierzchała W, Kon OM, Cosio B, Adcock IM, Barnes PJ. Cytokine production by bronchoalveolar lavage T lymphocytes in chronic obstructive pulmonary disease. J Allergy Clin Immunol. 2006;117(6):1484-1492.

7. Hackett TL, Holloway R, Holgate ST, Warner JA. Dynamics of pro-inflammatory and anti-inflammatory cytokine release during acute inflammation in chronic obstructive pulmonary disease: an ex vivo study. Respir Res. 2008;9:472.

8. Chaudhuri R, McSharry C, Brady J, et al. Sputum matrix metalloproteinase-12 in patients with chronic obstructive pulmonary disease and asthma: relationship to disease severity. J Allergy Clin Immunol. 2012;129(3):655.e8-663.e8.

9. Mocchegiani E, Giacconi R, Costarelli L. Costarelli, Metalloproteases/ anti-metalloproteases imbalance in chronic obstructive pulmonary disease: genetic factors and treatment implications. Curr Opin Pulm Med. 2011;17(Suppl 1):S11-S19.

10. Henson PM, Tuder RM. Apoptosis in the lung: induction, clearance and detection. Am J Physiol Lung Cell Mol Physiol. 2008;294(4): L601-L611.

11. Walsh GM. Defective apoptotic cell clearance in asthma and COPD - a new drug target for statins? Trends Pharmacol Sci. 2008;29(1):6-11.

12. Stringer KA, Tobias M, O’Neill HC, et al. Cigarette smoke extractinduced suppression of caspase-3-like activity impairs human neutrophil phagocytosis. Am J Physiol Lung Cell Mol Physiol. 2007; 292(6):L1572-L1579.

13. Cazzola M, Matera MG. Triple combinations in chronic obstructive pulmonary disease-is three better than two? Expert Opin Pharmacother. 2014;15(17):2475-2478.

14. Restrepo MI, Anzueto A. Macrolide antibiotics for prevention of chronic obstructive pulmonary disease exacerbations: are we there yet? Am J Respir Crit Care Med. 2014;190(1):1-2.
15. Dole M, Wilson FR, Fife WP. Hyperbarichydrogentherapy: a possibletreatmentforcancer. Science. 1975;190(421):152-154.

16. Ohsawa I, Ishikawa M, Takahashi K, et al. Hydrogen acts as a therapeutic antioxidant by selectively reducing cytotoxic oxygen radicals. Nat Med. 2007;13(6):688-694.

17. Manaenko A, Lekic T, Ma Q, et al. Hydrogen inhalation ameliorated mast cell mediated brain injury after ICH in mice. Crit Care Med. 2013; 41(5):1266.

18. Wang C, Li J, Liu Q, et al. Hydrogen-rich saline reduces oxidative stress and inflammation by inhibit of JNK and NF- $\mathrm{KB}$ activation in a rat model of amyloid-beta-induced Alzheimer's disease. Neurosci Lett. 2011;491(2):127-132.

19. Zhang H, Yu Y, Ma X, Yang T, Hu N, Wang G. 氢气吸入对严重 脓毒症小鼠血清炎性因子和肠损伤的影响 [Effects of hydrogen inhalation on serum pro-inflammatory factors and intestinal injury in mice with severe sepsis]. Zhonghua Wei Zhong Bing Ji Jiu Yi Xue. 2015;27:498-503. Chinese.

20. Huang CS, Kawamura T, Peng X, et al. Hydrogen inhalation reduced epithelial apoptosis in ventilator-induced lung injury via a mechanism involving nuclear factor-kappa B activation. Biochem Biophys Res Commun. 2011;408(2):253-258.

21. Kohama K, Yamashita H, Aoyama-Ishikawa M, et al. Hydrogen inhalation protects against acute lung injury induced by hemorrhagic shock and resuscitation. Surgery. 2015;158(2):399-407.

22. Zhou H, Fu Z, Wei Y, et al. Hydrogen inhalation decreases lung graft injury in brain-dead donor rats. J Heart Lung Transplant. 2013; 32(2):251-258.

23. Liu SL, Liu K, Sun Q, Liu WW, Tao HY, Sun XJ. Hydrogen Therapy may be a Novel and Effective Treatment for COPD. Front Pharmacol. 2011;2:19.

24. Jiang X, Yuan L, Li P, et al. Effect of simvastatin on 5-HT and 5-HTT in a rat model of pulmonary artery hypertension. Cell Physiol Biochem. 2015;37(5):1712-1724.

25. Wang L, Zhang B, Li Z, Li J, Liu Q, Sun W. Budesonide mitigates pathological changes in animal model of COPD through reducing neutrophil elastase expression. Int J Clin Exp Med. 2015;8(4): 5227.

26. Popescu LM, Gherghiceanu M, Hinescu ME, et al. Insights into the interstitium of ventricular myocardium: interstitial Cajal like cells (ICLC). J Cell Mol Med. 2006;10(2):429-458.

27. Iebba V, Totino V, Santangelo F, et al. Bdellovibrio bacteriovorus directly attacks Pseudomonas aeruginosa and Staphylococcus aureus Cystic fibrosis isolates. Front Microbiol. 2014;5:280.

28. Towbin H, Staehelin T, Gordon J. Electrophoretic transfer of proteins from polyacrylamide gels to nitrocellulose sheets: procedure and some applications. Proc Natl Acad Sci U S A. 1979;76(9):4350-4354.

29. Akahane T, Kurokawa Y, Yaegashi H, Satomi S, Takahashi T. Experimental ablation of emphysematous rat lung with Nd:YAG laser: lung changes studied by histopathology and SEM. Tohoku J Exp Med. 1998;185(2):119-129.

30. Liu W, Shan LP, Dong XS, et al. Combined early fluid resuscitation and hydrogen inhalation attenuates lung and intestine injury. World $J$ Gastroentero. 2013;19(4):492-502.

31. Yao L, Xu F, Luo C, et al. 氢气对高氧致肺泡II型上皮细胞损伤的保 护作用 [Protective effect of hydrogen against hyperoxia-induced type II alveolar epithelial cell injury]. Nan Fang Yi Ke Da Xие Xиe Bao. 2013;33:193-196. Chinese.

32. Ohta S. Molecular hydrogen is a novel antioxidant to efficiently reduce oxidative stress with potential for the improvement of mitochondrial diseases. Biochim Biophys Acta. 2012;1820(5):586-594.

33. Muñoz M, Heimesaat MM, Danker K, et al. Interleukin (IL)-23 mediates Toxoplasma gondii-induced immunopathology in the gut via matrixmetalloproteinase-2 and IL-22 but independent of IL-17. J Exp Med. 2009;206(13):3047-3059.

34. Ivanov II, McKenzie BS, Zhou L, et al. The orphan nuclear receptor ROR $\gamma t$ directs the differentiation program of proinflammatory IL-17+ T helper cells. Cell. 2006;126(6):1121-1133. 
35. Wakashin H, Hirose K, Maezawa Y, et al. IL-23 and Th17 cells enhance Th2-cell-mediated eosinophilic airway inflammation in mice. Am J Respir Crit Care Med. 2008;178(10):1023-1032.

36. Qiu X, Li H, Tang H, et al. Hydrogen inhalation ameliorates lipopolysaccharide-induced acute lung injury in mice. Int Immunopharmacol. 2011;11(12):2130-2137.

37. Chen Y, Thai P, Zhao YH, et al. Stimulation of airway mucin gene expression by interleukin (IL)-17 through IL-6 paracrine/autocrine loop. J Biol Chem. 2003;278(19):17036-17043.

38. Owen CA. Roles for proteinases in the pathogenesis of chronic obstructive pulmonary disease. Int J Chron Obstruct Pulmon Dis. 2008;3(2): 253-268.
39. Huang CS, Kawamura T, Lee S, et al. Hydrogen inhalation ameliorates ventilator-induced lung injury. Crit Care. 2010;14(6):R234.

40. Kawamura T, Huang CS, Peng X, et al. The effect of donor treatment with hydrogen on lung allograft function in rats. Surgery. 2011; 150(2):240-249.

41. Hayashida K, Sano M, Ohsawa I, et al. Inhalation of hydrogen gas reduces infarct size in the rat model of myocardial ischemia-reperfusion injury. Biochem Biophys Res Commun. 2008;373(1):30-35.

\section{Publish your work in this journal}

The International Journal of COPD is an international, peer-reviewed journal of therapeutics and pharmacology focusing on concise rapid reporting of clinical studies and reviews in COPD. Special focus is given to the pathophysiological processes underlying the disease, intervention programs, patient focused education, and self management protocols.

\section{Dovepress}

This journal is indexed on PubMed Central, MedLine and CAS. The manuscript management system is completely online and includes a very quick and fair peer-review system, which is all easy to use. Visit $\mathrm{http} / / / \mathrm{www}$.dovepress.com/testimonials.php to read real quotes from published authors. 